\title{
Socio-demographic and maternal predictors of adherence to 24-hour movement guidelines in Singaporean children
}

Bozhi Chen ${ }^{1}$, Jonathan Y. Bernard ${ }^{2,3}$, Natarajan Padmapriya ${ }^{4}$, Jiali Yao ${ }^{1}$, Claire Goh ${ }^{3}$, Kok Hian Tan ${ }^{5,6}$, Fabian Yap ${ }^{6,7,8}$, Yap-Seng Chong ${ }^{3,4}$, Lynette Shek ${ }^{4,9,10}$, Keith M. Godfrey ${ }^{11,12}$, Shiao-Yng Chan ${ }^{3,4}$, Johan G. Eriksson ${ }^{3,4}$ and Falk Müller-Riemenschneider ${ }^{1,13^{*}}$ (D)

\begin{abstract}
Purpose: Integrated 24-Hour Movement Guidelines provide specific recommendations on screen viewing (SV), moderate-to-vigorous physical activity (MVPA) and sleep to improve health of children and youth. However, few studies have examined whether these guidelines are met in young children, particularly in Asia. We evaluated adherence to integrated and individual guidelines and its predictors in 5.5-year-old Singaporean children.
\end{abstract}

Methods: Growing Up in Singapore towards Healthy Outcomes (GUSTO) is a mother-offspring birth cohort study. At age 5.5 years, child SV was reported by parents. Movement behaviours (MBs) were measured continuously using wrist-worn accelerometers over 7 consecutive days and nights. For accelerometer data including $\geq 3$ days with $\geq 16$ h/day we estimated mean $( \pm S D)$ daily MVPA, SV and nighttime sleep duration across the week. Adherence to integrated (Canadian/Australian) guidelines was defined as meeting all individual guidelines: $\geq 60$ min of MVPA/day, $\leq 2 \mathrm{~h}$ of screen time/day, and $9-11 \mathrm{~h}$ of sleep/night. Socio-demographic and maternal predictors collected at pregnancy enrolment and at 26-28 weeks' gestation were examined by multivariable logistic regression.

Results: Of 864 children followed up age 5.5 years, 547 (63.3\%) had both valid ActiGraph and questionnaire data (51.7\% boys and 58.3\% Chinese ethnicity). Children averaged $101.9( \pm 88.7) \mathrm{min} /$ day SV, $67.3( \pm 23.7) \mathrm{min} /$ day MVPA and 480.6 ( \pm 57.2) $\mathrm{min} /$ night sleep. Few children met integrated guidelines. Specifically, the proportions of children who met none, SV, MVPA, sleep and integrated guidelines were 11.2, 70.2, 59.6, 13.7 and 5.5\%, respectively. Multivariable analysis showed that maternal activity and television (TV) viewing were associated with meeting integrated guidelines (insufficiently vs. highly active (OR [95\% CI]): $0.11[0.01,0.95] ; 2-3$ vs. $\geq 3$ h TV: 3.52 [1.02, 12.22]). Examining higher adherence to individual guidelines, Chinese ethnicity, younger maternal age and lower maternal TV and sleep time were associated with greater SV; male sex, Malay ethnicity, higher birth order and higher maternal activity level were associated with greater MVPA; and older maternal age was associated with adherence to sleep guideline.

(Continued on next page)

\footnotetext{
* Correspondence: ephmf@nus.edu.sg

${ }^{1}$ Saw Swee Hock School of Public Health, National University of Singapore,

Tahir Foundation Building (Block MD1), 12 Science Drive 2, \#09-01v,

Singapore 117549, Singapore

${ }^{13}$ Institute for Social Medicine, Epidemiology and Health Economics, Charite

University Medical Centre, Berlin, Germany

Full list of author information is available at the end of the article
}

(c) The Author(s). 2019 Open Access This article is distributed under the terms of the Creative Commons Attribution 4.0 International License (http://creativecommons.org/licenses/by/4.0/), which permits unrestricted use, distribution, and reproduction in any medium, provided you give appropriate credit to the original author(s) and the source, provide a link to the Creative Commons license, and indicate if changes were made. The Creative Commons Public Domain Dedication waiver (http://creativecommons.org/publicdomain/zero/1.0/) applies to the data made available in this article, unless otherwise stated. 
(Continued from previous page)

Conclusions: Beyond individual behaviours, consideration of the full spectrum of MBs may be important to improve children's health. However, few Singaporean children adhere to integrated 24-h movement guidelines. Maternal behaviours as early as during pregnancy could be important targets for future interventions aiming to promote these MBs in children.

\section{Introduction}

Children's physical activity (PA), screen-based sedentary behaviour (SB) (also known as screen viewing (SV) and sleep are independently associated with health and well-being. Studies have consistently shown that higher levels of PA are associated with improved motor development, healthier cardio-metabolic function and better psychosocial health $[1,2]$. Greater SV among young children, on the other hand, has been associated with higher cardio-metabolic risk, unfavorable body composition and behavioural conduct, and lower self-esteem [3, 4]. Insufficient sleep duration has been associated with higher adiposity risk, decreased emotional regulation, less successful academic achievements and worse quality of life [5-7]. Further, the combination of these behaviours affect a number of important health indicators $[8,9]$. These behavioural patterns establish in early childhood and persist into adulthood [10]. To promote health and well-being in children and adults it is therefore essential to understand and improve the balance between these behaviours at young age.

Physical activity, SB and sleep represent the movement spectrum across the entire day and have been referred to as "movement behaviour (MB)" [11]. Consequently, it is flawed to view them individually because time spent in one behaviour is co-dependent with/on the other behaviours during the remaining time of the day. Since 2016, Canada [11, 12], Australia [13, 14], South Africa [15] and WHO [16] have developed integrated movement guidelines for children aged $0-17$ years, taking into consideration all behaviours that make up an entire day. While most of these guidelines focus only on children up to 5 years, Canada and Australia also provide recommendations for children aged 5-17 years. In the Canadian and Australian 24-Hour Movement Guidelines for children and youth, for instance, recommendations include sufficient PA (e.g. $\geq 60 \mathrm{~min} /$ day of MVPA), together with limited SV ( $\leq 2 \mathrm{~h} /$ day) and adequate sleep duration (e.g. 9-11 h/night for children aged 5-13).

Meeting the integrated guidelines appears to have a greater positive impact on a child's cognition [17], physical and psychological heath $[18,19]$, than meeting only one guideline or not meeting any guideline. As reported by the few available studies, adherence to integrated guidelines ranged from 11.9 to $30 \%$ in children [20-23]. However, these studies have largely been conducted in Canada or Australia and to the best of our knowledge, no study from Asia has yet been published. Existing studies on isolated
MBs in Asia have reported a high prevalence of physical inactivity [24], excessive time spend on screen devices [4, 25], and an average sleep duration that is shorter compared to children from the US or Europe [26]. Therefore, adherence to integrated guidelines may be even lower among Asian children.

Studies have explored potential predictors of single MB in young children [26-28]. As suggested by such studies, some socio-demographic (e.g. child's age and sex) and maternal factors (e.g. maternal age and activities) were associated with children's individual MB. Previous research has also shown strong links between pre-pregnancy behaviours and subsequent child health [29]; however, studies investigating maternal behavioural factors generally used cross-sectional study designs, and none explored maternal pre-pregnancy behaviours which could present a window of opportunity for health promotion activities to influence the manifestation of health behaviours in early childhood. Maternal behaviours during early pregnancy have also been reported to be associated with maternal physical and mental health [30]. Thus, maternal pre-pregnancy behaviours may be predictors of children's heath, through their associations with children's health behaviours during early childhood. To our knowledge, there is no study that investigated the association between these factors and adherence to integrated guidelines in young children.

Utilizing data from the Growing Up in Singapore Towards Healthy Outcomes (CUSTO) mother offspring study we aimed to address existing research gaps. Specifically, we aimed a) to investigate the proportion of children meeting individual (MVPA, SV, and sleep) and integrated movement guidelines at 5.5 years in a multi-ethnic Asian population, and b) to identify the socio-demographic and maternal prepregnancy factors associated with adherence to the integrated and individual guidelines.

\section{Methods}

\section{Study population}

This study was part of the Growing Up in Singapore Towards Healthy Outcomes (GUSTO) study, a mother-offspring birth cohort study examining earlylife factors that affect long-term health and development of children. Study design and detailed protocols have been described elsewhere [31]. Briefly, from June 
2009 to September 2010, pregnant women were recruited during their first ultrasound scan visit to two public maternity units in Singapore (KK Women's and Children's Hospital and National University Hospital). Inclusion criteria were: 1) being Singaporean citizens or permanent residents with homogeneous Chinese, Malay or India ethnicity; 2) intending to deliver in one of the two above-mentioned maternity units and remain in Singapore for the following 5 years. Of the 1247 pregnant women recruited, 1171 singleton newborns were included and followed up regularly. Written informed consent was obtained from all participants at enrolment. This study was approved by the National Healthcare Group Domain Specific Review Board and the SingHealth Centralised Institutional Review Board.

\section{Data collection}

As part of an interviewer-administered questionnaire, socio-demographic information was obtained at enrolment, including ethnicity (Chinese, Malay, India), maternal highest level of education (primary or secondary, post-secondary, university), marital status (single, married), monthly household income (<4000, 4000-5999, $\geq 6000$ Singapore dollars). Information on maternal age at delivery $(<30,30-35, \geq 35$ years) and the offspring's date of birth, sex and birth order (first-, second-or later-born) was extracted from medical records. Self-reported prepregnancy weight and height collected at the 26-28 weeks gestational visit were used to calculate pre-pregnancy BMI $\left(\mathrm{kg} / \mathrm{m}^{2}\right)$. BMI was categorized as underweight, normal weight, overweight and obese using cut-offs for Asian populations $\left(<18.5,18.5-23,23-27.5, \geq 27.5 \mathrm{~kg} / \mathrm{m}^{2}\right)$ [32]. Pre-pregnancy behavioural information (i.e. PA, television (TV)-viewing, sleep) was obtained through an intervieweradministered questionnaire at the 26-28-week visit. Six items assessing frequency and duration of PA at different intensities were adopted from a structured questionnaire [33] to determine the total time spent at each intensity level of maternal PA before pregnancy; PA was then categorized as insufficiently, sufficiently or highly active, as detailed previously [34]. Energy expended on PA at each intensity was derived by multiplying weekly total minutes and its corresponding metabolic equivalent task (MET) value (3.3, 4.0 and 8.0 for light, moderate and vigorous intensity respectively [35]). Total energy expenditure on PA per week was calculated by summing energy expenditure on PA at all intensities, then categorized into insufficiently active $(<600$ MET-minutes/week), sufficiently active (600-3000 MET- minutes/week), and highly active ( $\geq 3000$ MET- minutes/week). In addition to PA assessment, maternal TV-viewing time and total sleep duration during a 24-h period before pregnancy were also assessed as part of the questionnaire at 26-28-week visit. TV-viewing time was categorized into three levels $(<2,2-3, \geq 3 \mathrm{~h})$, consistent with literature suggesting that children whose parents watched TV more than $2 \mathrm{~h}$ /day were more likely to have greater SV [36]. Our categorization of daily total sleep duration $(<7,7-9, \geq 9 \mathrm{~h})$ was based on the recommended sleep range (i.e. 7-9 h/day) for adults [37].

\section{Accelerometer-measured physical activity (PA) and sleep duration among children}

PA was measured objectively using triaxial accelerometers (ActiGraph ${ }^{\text {тм }}$ wGT3X-BT) which were set to record raw acceleration data. At the age 5.5 years study visit, researchers attached an accelerometer on each child's non-dominant wrist with a non-removable strap. Accelerometers were set to start at midnight on the following day after the home visit; no end date or time were set. Children were asked to wear the accelerometer for 7 days and nights and remove it on the 8th day; allowing to record 24-h activities throughout a week.

Data were collected at a rate of $80 \mathrm{~Hz}$ and downloaded in raw format (GT3X) with the Actilife software (version 6.13). Raw data were processed in $R$ using the GGIR package (version 1.6-0) [38]. Raw triaxial accelerometer signals were auto-calibrated [39] and converted into gravity-corrected vector magnitude units, termed the Euclidean norm minus one (ENMO) [38]. Accelerometer wear time inclusion criteria were a minimum of $16 \mathrm{~h}$ /day for at least 3 days. Non-wear time was estimated based on the standard deviation and value range of each accelerometer axis, using a 60-min window with 15-min increments. For each 15 -min period detected as non-wear time over the valid wearing days, the invalid data were imputed using the mean value of valid data at same time points on other days [40]. Sleep duration was estimated using the method by van Hees et al. as part of GGIR processing [41]. We used the acceleration intensity thresholds $(\mathrm{mg})$ to classify activity during waking time into $\mathrm{SB}(\mathrm{ENMO} \leq 35.0 \mathrm{~m} g)$, light PA (LPA, ENMO 35.0-200.0 mg) and MVPA (ENMO> $200.0 \mathrm{mg}$ ), which were identified by Hildebrand et al.'s prediction eqs. [42].

\section{Proxy-reported screen viewing (SV) among children}

During the study visit at age 5.5 years, parents were asked to report the amount of time their child spent watching/using TV/DVD, computers, mobile devices and video game consoles on weekdays, Saturday and Sunday (see Additional file 1: Table S1 for the items). The items were from the preschool-age physical activity questionnaire (Pre-PAQ), a questionnaire validated in preschool-aged children [43]. Pre-PAQ was modified slightly by including one additional question about time spent on mobile devices, to make it more applicable to the current Singaporean context. Daily device-specific SV time was calculated as follows: ((Weekdays $\times 5)+$ 
Saturday + Sunday) / 7. Total SV was calculated by adding up the daily SV time of each device.

\section{Statistical analysis}

Means \pm standard deviations (SD), medians (interquartile range $(\mathrm{IQR})$ ) for continuous, frequencies and percentages for categorical variables were estimated. Pearson's $\mathrm{X} 2$ test was conducted to compare the sociodemographic characteristics (i.e. child's sex, ethnicity, birth order; household income and maternal education) of children who were included with those not included in the further analyses. Our study applies the Canadian and Australian 24-Hour Movement Guidelines for children and youth [11, 14], because the study sample fits better in their target age group 5-17 years. We calculated the proportions of children meeting the weekly averaged MVPA ( $\geq 60 \mathrm{~min} /$ day), SV ( $\leq 2 \mathrm{~h} /$ day), sleep (9-11 $\mathrm{h} /$ night) guideline [11], and their combination to determine the proportion of children meeting the integrated guidelines.

The probabilities that a child met the integrated guidelines and its individual components were modelled using univariate and multivariable logistic regression. In the multivariable model, we examined the following correlates: child's age (in years), sex, ethnicity, birth order, household income, maternal education, maternal prepregnancy BMI, maternal age at delivery, maternal PA, TV and sleep before pregnancy. All statistical analyses were conducted using $R$ version 3.4.3.

\section{Results}

Of 864 children who attended the clinic visit at age 5.5 years, $547(63.3 \%)$ had both parent-reported SV and valid accelerometer data (Fig. 1). No significant difference $(P>0.05$ for all variables) was observed between children included in the study and those not included (data not shown). Detailed child and maternal characteristics are presented in Table 1 . Briefly, the mean age was $5.5( \pm 0.1)$ years, $51.7 \%$ were boys and $58.3 \%$ were of Chinese ethnicity, with the remainder being of Malay (24.1\%) or Indian (17.6\%) ethnicity.

Table 2 shows the descriptive characteristics of parent-reported SV, accelerometer-measured PA and sleep, and the proportions of children meeting the individual and integrated guidelines. On average, children spent $101.9 \pm$ minutes on total SV (TV: $49.4 \pm 49.4 \mathrm{~min}$; mobile devices: $34.8 \pm 47.3$ ), engaged in $431.9 \pm 67.3 \mathrm{~min} /$ day of PA (including $67.3 \pm 23.7 \mathrm{~min}$ of MVPA), and spent $480.6 \pm 57.2 \mathrm{~min}$ sleeping at night. Figure 2 illustrates the proportions of the children meeting the SV, MVPA, and sleep guidelines, as well as the combination of these: $5.5 \%$ of the children met the integrated guidelines. This proportion ranged from 2.0 to $8.3 \%$ across different subgroups. Children of an insufficiently active mother before pregnancy had the lowest adherence to integrated guidelines, whereas Indian children had the highest. In terms of meeting individual guidelines, $70.2 \%$ of the children met SV guideline, with highest proportion $(81.8 \%)$ in children of mothers educated to university level and lowest (53.0\%) in Malay children; 59.6\% met the MVPA guideline, with the highest proportion (67.8\%) in boys and lowest (45.5\%) in children of an insufficiently active mother before pregnancy; $13.7 \%$ met sleep guidelines with the highest proportion (20.3\%) in children of mothers older than 35 years at delivery and the lowest (7.0\%) in children of mothers sleeping less than $7 \mathrm{~h}$ before pregnancy. Overall, $11.2 \%$ did not meet any guidelines, with the highest proportion $(17.2 \%)$ in children of an insufficiently active mother before pregnancy and the lowest (3.8\%) in children from families with a monthly household income more than 6000 SGD. Details of the proportions of children meeting no guidelines, individual and integrated guidelines by each socio-demographic or maternal factor are summarised in Additional file 1: Table S2.

Table 3 shows the adjusted odds ratios for the associations of socio-demographic and maternal factors with adherence to the integrated and individual guidelines at age 5.5 years. Only higher maternal PA level (sufficiently active: $0.67[0.29,1.56]$; insufficiently active: $0.11[0.01$, $0.95])$ and lower maternal TV time ( $<2 \mathrm{~h} \mathrm{TV}: 1.58$ [0.47, 5.28]; 2-3: 3.52 [1.02, 12.22]) before pregnancy were significant predictors of higher adherence to integrated guidelines. In addition, compared to Chinese children, Malay children were less likely to meet SV $(0.33$ [0.19, 0.58]) and more likely to meet MVPA guidelines (1.76 $[1.03,3.00])$. Younger maternal age at delivery was associated with higher adherence to SV (<30 years: 1.73 [1.00, 2.97]; 30-35: 1.23 [0.72, 2.09]) but lower adherence to sleep guidelines (<30 years: $0.63[0.33,1.2]$; $30-$ 35: $0.41[0.20,0.84])$. Children of an insufficiently active mother before pregnancy were less likely to meet the MVPA guideline $(0.44[0.25,0.78])$; those whose mothers watched less than $2 \mathrm{~h}$ TV per day before pregnancy were more likely to meet SV guidelines (1.73 [1.05, 2.84]). Maternal pre-pregnancy sleep time was significantly associated with children's adherence to SV $(<7 \mathrm{~h} /$ night: 2.15 [1.05, 4.42]; 7-9: 1.49 [0.92, 2.41]). Other predictors significantly associated with higher adherence to MVPA were: being a boy, or a second- or later-born child.

\section{Discussion}

In our multi-ethnic Singaporean mother-offspring cohort, we found that only $5.5 \%$ of children aged 5.5 years met integrated 24-Hour Movement Guidelines and $11.2 \%$ of the children met none of the movement guidelines. Accordingly, a substantial proportion of children did not meet individual guidelines, which was particularly frequent with regard to sleep. Pre-pregnancy maternal PA and TV time were the only significant predictors 


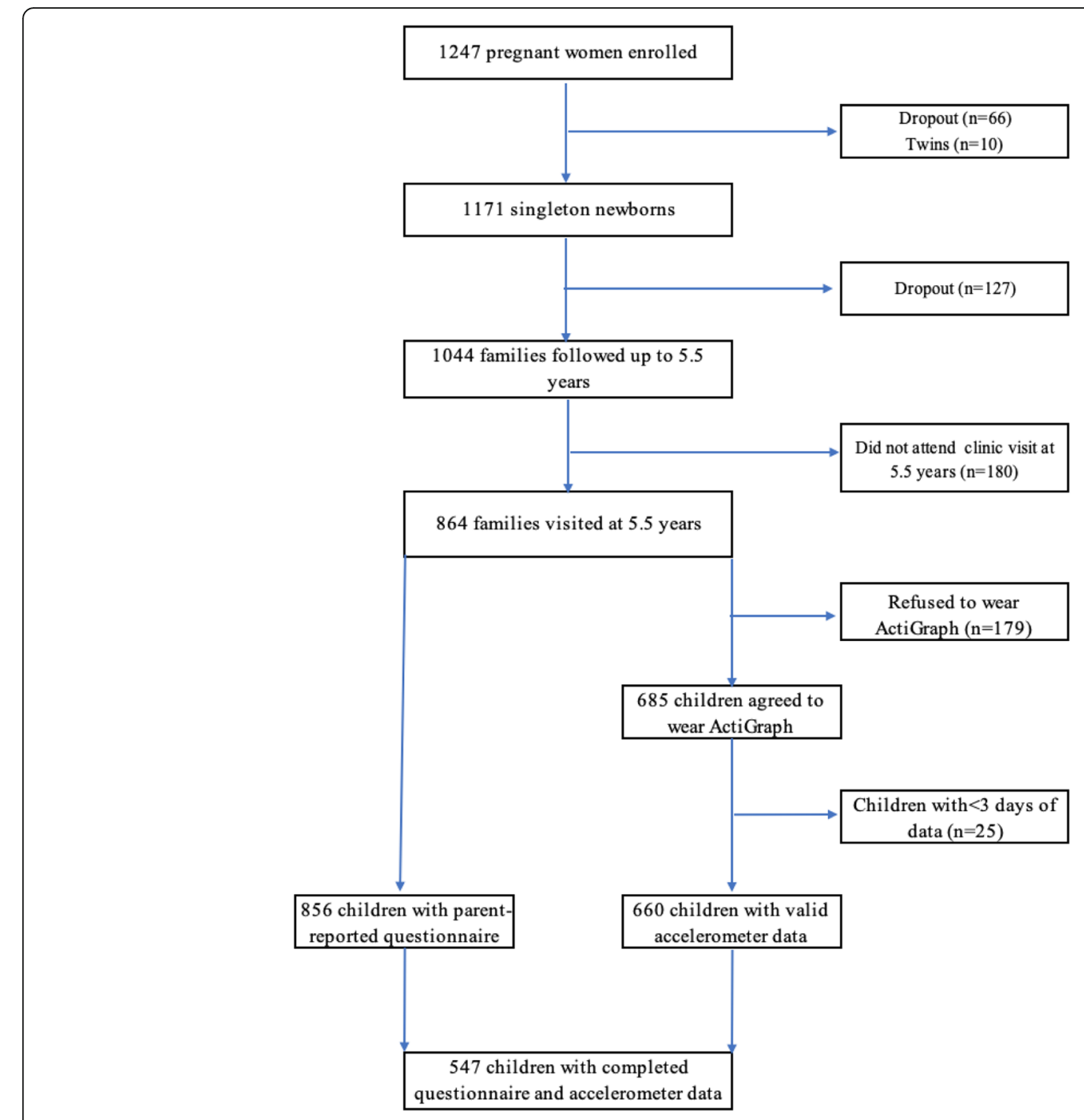

Fig. 1 Flow diagram of the GUSTO study participants followed up to 5.5 year

of adherence to integrated guidelines at 5.5 years of age; other socio-demographic and maternal predictors were associated with individual guidelines, demonstrating inconsistent patterns.

A previous study including children from different continents, demonstrated that meeting integrated guidelines was associated with the lowest odds ratio of obesity when compared with meeting individual or no guidelines [19]. Similar findings have also been reported in a study of American children [44]. Despite this evidence for the importance of considering all MBs, to our knowledge no study has examined the adherence to 24-Hour Movement Guidelines among children at similar age as in our study. Similar to our findings, Roberts et al. [21] reported that among Canadian children aged 5-11 years, 70.6 and $46.8 \%$ met SV and MVPA guidelines, respectively. However, much higher adherence to integrated (29.6\%) and sleep guidelines $(82.6 \%)$ was reported in their study. The low adherence in the current study is consistent with previous studies investigating the adherence to the Canadian 24-Hour Movement Guidelines for Children and Youth in older children. For instance, Walsh et al. [17] reported that $5.0 \%$ of $8-10$ year olds met the integrated guidelines in the U.S. In another large 12-country study (including 8 Western, 2 Asian and 2 African countries) of 6128 children aged 9-11 years, $7.2 \%$ of the children met integrated guidelines, with the lowest adherence (1.5\%) in China [19]. Possible reasons for different behavioural patterns of preschool-aged children in Asia could be a stronger academic focus in society and a tendency for longer preschool hours among children in Asia [45]. Inadequate play opportunities for the enhancement of PA 
Table 1 Characteristics of 5.5-year-old children and their mother in the GUSTO study ( $N=547)$

\begin{tabular}{|c|c|c|}
\hline & $\mathrm{N}$ & Mean \pm SD or $\%$ \\
\hline Child's age (year) & 547 & $5.5 \pm 0.1$ \\
\hline \multicolumn{3}{|l|}{ Sex } \\
\hline Boy & 283 & 51.7 \\
\hline Girl & 264 & 48.3 \\
\hline \multicolumn{3}{|l|}{ Ethnicity } \\
\hline Chinese & 319 & 58.3 \\
\hline Malay & 132 & 24.1 \\
\hline Indian & 96 & 17.6 \\
\hline \multicolumn{3}{|l|}{ Birth order } \\
\hline First-born & 244 & 44.6 \\
\hline Second-or later-born & 303 & 55.4 \\
\hline \multicolumn{3}{|c|}{ Household incomes (SGD/month) } \\
\hline$<4000$ & 237 & 46.1 \\
\hline $4000-5999$ & 117 & 22.8 \\
\hline$\geq 6000$ & 160 & 31.1 \\
\hline missing, $n$ & 33 & \\
\hline \multicolumn{3}{|l|}{ Maternal education } \\
\hline University & 187 & 34.4 \\
\hline Post-secondary & 190 & 34.9 \\
\hline Primary or secondary & 167 & 30.7 \\
\hline missing, $n$ & 3 & \\
\hline \multicolumn{3}{|c|}{ Pre-pregnancy weight status } \\
\hline Underweight/normal & 340 & 62.2 \\
\hline Overweight & 133 & 24.3 \\
\hline Obese & 74 & 13.5 \\
\hline \multicolumn{3}{|l|}{ Maternal age at delivery } \\
\hline$<30$ & 223 & 40.8 \\
\hline $30-35$ & 171 & 31.3 \\
\hline$\geq 35$ & 153 & 28.0 \\
\hline \multicolumn{3}{|l|}{$\begin{array}{l}\text { Maternal physical activity } \\
\text { before pregnancy }\end{array}$} \\
\hline Insufficiently active & 99 & 18.4 \\
\hline Sufficiently active & 296 & 54.9 \\
\hline Highly active & 144 & 26.7 \\
\hline missing, $n$ & 8 & \\
\hline \multicolumn{3}{|c|}{$\begin{array}{l}\text { Maternal daily television-viewing } \\
\text { time before pregnancy }\end{array}$} \\
\hline$<2 \mathrm{~h}$ & 260 & 48.1 \\
\hline $2-3 h$ & 133 & 24.6 \\
\hline$\geq 3 \mathrm{~h}$ & 147 & 27.2 \\
\hline missing, $n$ & 7 & \\
\hline \multicolumn{3}{|c|}{$\begin{array}{l}\text { Maternal daily total sleep time } \\
\text { before pregnancy }\end{array}$} \\
\hline$<7 \mathrm{~h}$ & 71 & 13.1 \\
\hline $7-9 h$ & 335 & 62.0 \\
\hline$\geq 9 \mathrm{~h}$ & 134 & 24.8 \\
\hline missing, $n$ & 7 & \\
\hline
\end{tabular}

Table 2 Daily time (min/day) spent in self-reported screen viewing and accelerometer-measured physical activity and sleep at age $5.5 \mathrm{y}$ in the GUSTO cohort $(\mathrm{N}=547)$

\begin{tabular}{lll}
\hline & Mean \pm SD & Median (IQR) \\
\hline Screen viewing (total) & $101.9 \pm 88.7$ & $77.1(42.1-140.7)$ \\
Television & $49.4 \pm 49.4$ & $37.1(9.3-64.3)$ \\
Computer & $12.6 \pm 28.5$ & $0.0(0.0-17.1)$ \\
Mobile devices & $34.8 \pm 47.3$ & $17.1(0.0-51.4)$ \\
Game consoles & $3.6 \pm 14.7$ & $0.0(0.0-0.0)$ \\
Physical activity (total) & $431.9 \pm 67.3$ & $437.9(388.9-477.4)$ \\
Light intensity & $364.6 \pm 57.0$ & $371.3(324.6-401.0)$ \\
Moderate-to-vigorous intensity & $67.3 \pm 23.7$ & $64.8(49.8-81.6)$ \\
Sleep duration (total) & $538.8 \pm 58.1$ & $542.0(501.3-578.8)$ \\
Night-time sleep & $480.6 \pm 57.2$ & $483.6(442.2-524.0)$ \\
Daytime sleep & $58.3 \pm 29.2$ & $56.0(37.3-74.7)$ \\
\hline Abbreviation: SD (standard deviation); IQR interquartile range)
\end{tabular}

are likely to occur inside preschool and additional enrichment classes may leave little time for children to play outside the school environment [46]. Although a relatively high proportion of children met SV guideline in our sample, it is still concerning that almost $30 \%$ spent excessive time on SV. The proportion of children meeting sleep recommendations in this study was particularly small and children slept less than $9 \mathrm{~h}$ per night on average. These findings are consistent with previous evidence that young Singaporean children spent an average of only $8.8 \mathrm{~h}$ on night-time sleep [47]. Studies among similar-aged children from other high-income countries/regions in Asia have

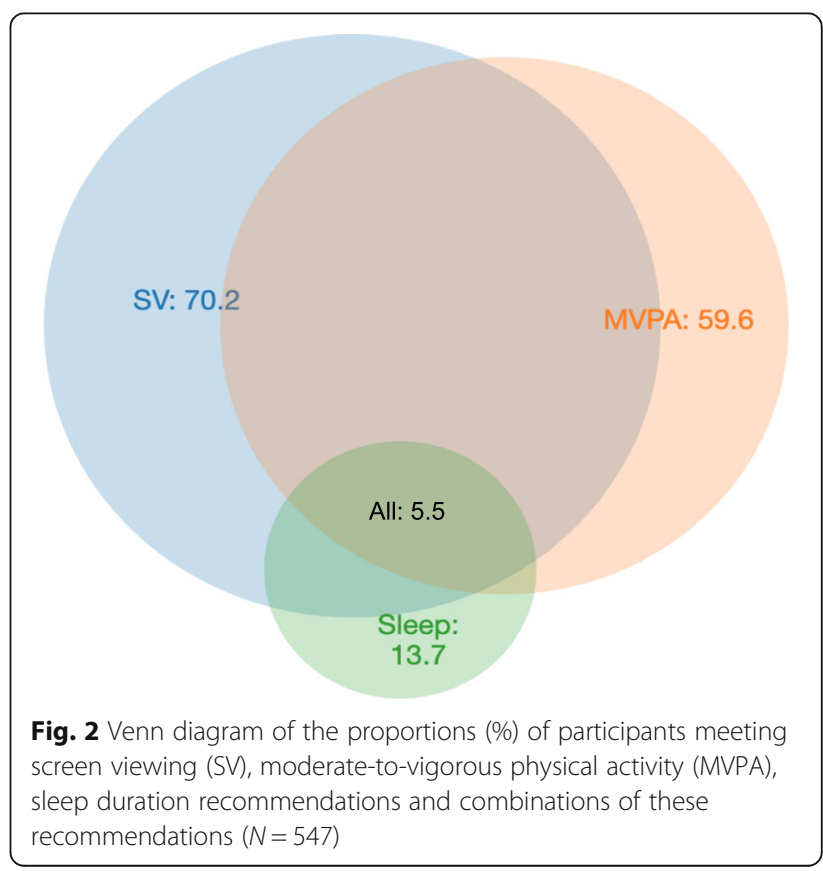


Table 3 Adjusted associations of socio-demographic and maternal factors with adherence to screen viewing (SV), moderate-tovigorous physical activity (MVPA), sleep duration recommendations and combinations of these recommendations

\begin{tabular}{|c|c|c|c|c|}
\hline & All & SV & MVPA & Sleep \\
\hline & OR $(95 \% \mathrm{Cl})$ & OR $(95 \% \mathrm{Cl})$ & OR $(95 \% \mathrm{Cl})$ & OR $(95 \% \mathrm{Cl})$ \\
\hline \multicolumn{5}{|l|}{ Sex (ref: girl) } \\
\hline Boy & $0.81(0.36,1.80)$ & $1.20(0.80,1.80)$ & $1.94(1.33,2.81)$ & $0.94(0.56,1.59)$ \\
\hline \multicolumn{5}{|l|}{ Ethnicity (ref: Chinese) } \\
\hline Malay & $1.11(0.34,3.65)$ & $0.33(0.19,0.58)$ & $1.76(1.03,3.00)$ & $1.85(0.90,3.81)$ \\
\hline Indian & $1.54(0.52,4.55)$ & $0.90(0.49,1.66)$ & $1.15(0.66,1.99)$ & $1.55(0.73,3.32)$ \\
\hline \multicolumn{5}{|l|}{ Birth order(ref: first-born) } \\
\hline Second-or later-born & $2.16(0.84,5.58)$ & $0.76(0.48,1.19)$ & $1.59(1.05,2.40)$ & $1.42(0.79,2.57)$ \\
\hline \multicolumn{5}{|l|}{$\begin{array}{l}\text { Maternal education } \\
\text { (ref: university) }\end{array}$} \\
\hline Primary or secondary & $0.99(0.28,3.47)$ & $0.82(0.42,1.62)$ & $0.67(0.36,1.25)$ & $1.52(0.64,3.60)$ \\
\hline Post-secondary & $1.08(0.35,3.30)$ & $0.64(0.35,1.16)$ & $1.02(0.60,1.74)$ & $1.02(0.46,2.24)$ \\
\hline \multicolumn{5}{|c|}{$\begin{array}{l}\text { Household incomes (ref: }<4000 \\
\text { SGD/month) }\end{array}$} \\
\hline $4000-5999$ & $0.62(0.18,2.15)$ & $0.83(0.48,1.42)$ & $1.49(0.89,2.50)$ & $0.69(0.31,1.53)$ \\
\hline$\geq 6000$ & $1.38(0.41,4.58)$ & $1.25(0.64,2.43)$ & $1.62(0.89,2.97)$ & $1.61(0.70,3.70)$ \\
\hline \multicolumn{5}{|c|}{$\begin{array}{l}\text { Pre-pregnancy weight status } \\
\text { (ref: underweight/normal) }\end{array}$} \\
\hline Overweight & $0.99(0.37,2.67)$ & $0.86(0.52,1.41)$ & $1.02(0.64,1.63)$ & $1.45(0.77,2.73)$ \\
\hline Obese & $0.55(0.14,2.17)$ & $0.58(0.32,1.06)$ & $0.83(0.46,1.50)$ & $1.13(0.51,2.51)$ \\
\hline \multicolumn{5}{|c|}{ Maternal age at delivery (ref: $\geq 35$ ) } \\
\hline$<30$ & $0.78(0.29,2.14)$ & $1.73(1.00,2.97)$ & $1.33(0.81,2.17)$ & $0.63(0.33,1.20)$ \\
\hline $30-35$ & $0.43(0.15,1.26)$ & $1.23(0.72,2.09)$ & $1.18(0.73,1.92)$ & $0.41(0.20,0.84)$ \\
\hline \multicolumn{5}{|c|}{$\begin{array}{l}\text { Maternal physical activity before } \\
\text { pregnancy (ref: highly active) }\end{array}$} \\
\hline Sufficiently active & $0.67(0.29,1.56)$ & $1.10(0.68,1.79)$ & $0.79(0.50,1.24)$ & $1.01(0.55,1.88)$ \\
\hline Insufficiently active & $0.11(0.01,0.95)$ & $0.79(0.43,1.47)$ & $0.44(0.25,0.78)$ & $1.24(0.56,2.75)$ \\
\hline \multicolumn{5}{|c|}{$\begin{array}{l}\text { Maternal daily television-viewing } \\
\text { time before pregnancy (ref: } \geq 3 \mathrm{~h} \text { ) }\end{array}$} \\
\hline$<2 \mathrm{~h}$ & $1.58(0.47,5.28)$ & $1.73(1.05,2.84)$ & $0.83(0.51,1.33)$ & $1.22(0.63,2.39)$ \\
\hline $2-3 \mathrm{~h}$ & $3.52(1.02,12.22)$ & $1.03(0.60,1.78)$ & $0.97(0.57,1.66)$ & $1.32(0.62,2.79)$ \\
\hline \multicolumn{5}{|c|}{$\begin{array}{l}\text { Maternal daily sleep time before } \\
\text { pregnancy (ref: } \geq 9 \text { h/night) }\end{array}$} \\
\hline$<7 \mathrm{~h}$ & $0.37(0.07,1.98)$ & $2.15(1.05,4.42)$ & $0.71(0.37,1.37)$ & $0.43(0.15,1.29)$ \\
\hline $7-9 h$ & $0.90(0.35,2.33)$ & $1.49(0.92,2.41)$ & $0.76(0.48,1.20)$ & $1.19(0.64,2.23)$ \\
\hline
\end{tabular}

Note: logistic regression was conducted to test the association between predictors and meeting guidelines; all predictors were included in each model; bold: significant associations $(p<0.05)$

reported similar observations [48, 49]. These estimates are much lower than those in Western countries, such as Australia [23], Canada [22], the U.S. [50], or European countries [51]. The differences of night-time sleep duration between these Western studies and our current study may be partly due to discrepancies in daytime napping behaviour across cultures [52], and nap duration has been shown to negatively correlate with night-time sleep duration in young children [53]. In Singapore and many other Asian countries and regions, napping is an important part of preschool daily schedule and children at this age are known to have mandatory afternoon naps at preschools [47]; on the contrary, this may not be possible for children in most Western countries due to a shorter preschool day. Children in the current study napped for around $1 \mathrm{~h}$ /day on average, whereas very few children of similar age have been reported to nap in Western countries [51, 54]. Considering napping in addition to nigh-time sleep increased the proportion of children 
meeting the sleep and integrated guidelines in our study considerably. However, the proportions of children meeting sleep guidelines remained lower than in Western preschool children. These results suggest that the current movement guidelines developed in Western countries may not be directly applicable to Asia, because they do not take these specific cultural aspects of sleeping and napping behaviour into consideration. When developing integrated guidelines for Singapore or Asia it may therefore be necessary to pay particular attention to the element of sleep and napping behaviour.

Understanding factors that contribute to low adherence towards integrated movement guidelines is necessary for health promotion efforts to control the childhood obesity epidemics [55]. In the current study, only higher pre-pregnancy maternal PA and TV time less than $3 \mathrm{~h} /$ day were associated with higher adherence to integrated guidelines. Maternal PA and TV time were also associated with children's adherence to MVPA and SV, respectively. These findings expand on previous studies reporting cross-sectional associations between maternal and children's behaviours [56-58], re-iterating the importance of targeting maternal behavioural factors in order to promote children's health behaviours. Previous research indicated that maternal sleep/wake patterns affect the sleep/wake patterns of their children [59], but we did not find a link between maternal sleep before pregnancy with children's adherence to sleep guideline. However, we cannot rule out the possibility that current maternal sleep may be important. Previous systematic reviews $[59,60]$ have highlighted the importance of engaging and supporting parents in the promotion of children's healthy behaviours, however, health promotion efforts have tended to focus on school settings. A systematic review of existing intervention studies in Asia, reported that all but one study occurred in a schoolbased setting and all targeted children at school age or above [61]. In light of our findings and previous evidence [25] with regards to the impact of detrimental parental behaviours (e.g. excessive SV and limited PA levels), it may be necessary for future interventions to also involve parents, with additional efforts on parental behaviours. Especially during early pregnancy women may be open to health promoting messages and activities which are beneficial for both themselves and their child in the future [62].

The lack of other consistent predictors of adherence to integrated guidelines is likely due to the fact that predictors of individual guidelines were highly variable and behaviour-specific. For instance, younger maternal age was significantly associated with higher adherence to SV but a lower adherence to sleep guidelines. Children of mothers younger than 35 years were more likely to sleep 9-11 h, which confirms previous evidence that children with younger mothers tend to sleep more [63]. Although maternal pre-pregnancy weight was not a predictor of children's behaviours at 5.5 years, previous cross-sectional studies have found associations between maternal weight and children's PA and SB in Western populations [64]. Apart from maternal predictors, girls were less likely to meet MVPA guideline at 5.5 years in this study. Our finding is consistent with other studies $[27,65,66]$ suggesting sex differences in PA may be observed early in life, warranting early intervention to promote PA in girls. Contrary to previous studies [67-69], we did not observe significant sex differences in SV or sleep guideline adherence in our sample. As studies [70, 71] have suggested that boys spend more time playing screen devices after age 5 years, sex differences in SV may emerge as they age. In addition to age, our study reported that Malay children were more likely to adhere to MVPA but less likely to SV guideline than Chinese. Although the relationship between ethnicity and childhood SV may be country- and context-specific, the available literature suggests that children from ethnic majorities spend less time on screen devices [18, 24-26].

This is the first study to assess adherence to MVPA, $\mathrm{SV}$ and sleep of the 24-h movement guidelines and to identify the main predictors of adherence to these guidelines in an Asian population. We assessed a wide range of socio-demographic and maternal predictors and used objectively-measured PA and sleep time. In addition to providing locally specific information that may help develop national health promotion strategies, this study provides information that will enable international comparisons of adherence to integrated movement guidelines among young children, and their predictors. For instance, our findings may be able to inform the development of national report card on PA for children as part of global initiatives in promoting PA [72]. Therefore, our results may provide important information for both local- and international-level efforts to promote children's healthy living.

However, we acknowledge certain limitations of our study. First, children's time spent on screen devices was reported by parents, which could be underreported when children were at childcare centres or parents were not at home. However, these items are derived from a validated questionnaire and have been used in other studies [73, 74]. Second, pre-pregnancy behavioural data (including PA, TV and sleep duration) were limited to mothers' self-reports with potential recall bias. Thirdly, we did not capture information on current maternal behaviours. Hence, there might be a chance that pre-pregnancy behaviours was just a reflection of their current behaviours. Fourthly, the current 24-Hour Movement Guidelines do not account for napping behaviour for children aged 5 years and above, which is 
common among Asian children. This may result in an underestimation of the proportion of children meeting sleep and integrated guidelines. Integrated guidelines for Singapore or other Asian countries may therefore have to include recommendations on the total sleep duration in a 24-h period rather than only night time sleep. Finally, although our sample is very similar to the entire GUSTO sample, the cohort does not represent the entire Singaporean population. For instance, Malay and Indian families were overrepresented purposely at inclusion; recruited mothers were also less likely to hold a university degree than the women from the general population of the same age range [31]. Generalizing our results should therefore be made with caution.

\section{Conclusions}

Only about 1 in 20 Singapore preschool-aged children met integrated movement guidelines and about 1 in 10 failed to meet any guideline. The situation in Singapore and other Asian countries/regions appears worse than in Western countries. Accordingly, the proportion of children not meeting individual MVPA and SV guidelines was relatively high. Moreover, the proportion of children not meeting sleep guidelines was particularly high with an average sleep duration shorter than recommended for the age group. To facilitate better monitoring and surveillance of these behaviours, the adaption of integrated movement guidelines for Singapore and possibly Asia may be advisable. At the same time, considering the common napping behaviours in Asia, it may be necessary to adapt current guidelines in such a way that they include total sleep duration during a 24-h period. Meanwhile, since most interventions have solely targeted individual behaviours, additional strategies to promote movement-related behaviours comprehensively may be particularly important to promote children's health and tackle growing concerns about childhood obesity. Future interventions should also target maternal behaviours while their children are very young or even during pregnancy.

\section{Additional file}

Additional file 1: Table S1. Which of the following activities did your child do yesterday and last weekend? (If yes, record the times for each activity). Table S2. Proportion (\%) of children meeting no guidelines, screen viewing (SV), moderate-to-vigorous physical activity (MVPA), sleep duration recommendations and combinations of these recommendations, overall and by socio-demographic and maternal predictors. (DOCX $17 \mathrm{~kb}$ ).

\section{Abbreviations}

GUSTO: Growing Up in Singapore Towards healthy Outcomes;

MB: Movement behaviour; MVPA: moderate-to-vigorous physical activity;

PA: Physical activity; SB: Sedentary behaviour; SV: screen viewing;

$\mathrm{TV}$ : television viewing

\section{Acknowledgements}

We thank GUSTO study group, operational managers, research fellows, study coordinators and data management team. We greatly appreciate voluntary participation of all participants, and cooperation of KK Women's and Children's Hospital and National University Hospital. The GUSTO study group includes Allan Sheppard, Amutha Chinnadurai, Anne Eng Neo Goh, Anne Rifkin-Graboi, Anqi Qiu, Arijit Biswas, Bee Wah Lee, Birit F.P. Broekman, Boon Long Quah, Borys Shuter, Chai Kiat Chng, Cheryl Ngo, Choon Looi Bong, Christiani Jeyakumar Henry, Claudia Chi, Cornelia Yin Ing Chee, Yam Thiam Daniel Goh, Doris Fok, E Shyong Tai, Elaine Tham, Elaine Quah Phaik Ling, Evelyn Chung Ning Law, Evelyn Xiu Ling Loo, Fabian Yap, Falk Müller-Riemenschneider, George Seow Heong Yeo, Helen Chen, Heng Hao Tan, Hugo P S van Bever, Iliana Magiati, Inez Bik Yun Wong, Ivy Yee-Man Lau, Izzuddin Bin Mohd Aris, Jeevesh Kapur, Jenny L. Richmond, Jerry Kok Yen Chan, Joanna D. Holbrook, Joanne Yoong, Joao N. Ferreira., Jonathan Tze Liang Choo, Jonathan Y. Bernard, Joshua J. Gooley, Keith M. Godfrey, Kenneth Kwek, Kok Hian Tan, Krishnamoorthy Niduvaje, Kuan Jin Lee, Leher Singh, Lieng Hsi Ling, Lin Lin Su, Ling-Wei Chen, Lourdes Mary Daniel, Lynette P Shek, Marielle V. Fortier, Mark Hanson, Mary Foong-Fong Chong, Mary Rauff, Mei Chien Chua, Melvin Khee-Shing Leow, Michael Meaney, Mya Thway Tint, Neerja Karnani, Ngee Lek, Oon Hoe Teoh, P. C. Wong, Paulin Tay Straughan, Peter D. Gluckman, Pratibha Agarwal, Queenie Ling Jun Li, Rob M. van Dam, Salome A. Rebello, Seang-Mei Saw, See Ling Loy, S. Sendhil Velan, Seng Bin Ang, Shang Chee Chong, Sharon Ng, Shiao-Yng Chan, Shirong Cai, Shu-E Soh, Sok Bee Lim, Stella Tsotsi, Chin-Ying Stephen Hsu, Sue Anne Toh, Swee Chye Quek, Victor Samuel Rajadurai, Walter Stunkel, Wayne Cutfield, Wee Meng Han, Wei Wei Pang, Yap-Seng Chong, Yin Bun Cheung, Yiong Huak Chan and Yung Seng Lee.

\section{Authors' contributions}

KHT, FY, YSC, LS and KMG conceived and designed the cohort study; BC, JYB, JGE and FMR designed the present work; NP and SC contributed to data collection; BC, NP, JYB, JY, CG and FMR contributed to data analysis and interpretation; BC drafted the manuscript, and JYB, JGE and FMR added important intellectual content; all authors read and approved the final manuscript.

\section{Funding}

This research was supported by the Singapore National Research Foundation under its Translational and Clinical Research (TCR) Flagship Programme and administered by the Singapore Ministry of Health's National Medical Research Council (NMRC), Singapore- NMRC/TCR/004-NUS/2008; NMRC/TCR/ 012-NUHS/2014. Additional funding was provided by the Singapore Institute for Clinical Sciences, Agency for Science Technology and Research (A*STAR), Singapore. KMG is supported by the National Institute for Health Research through the NIHR Southampton Biomedical Research Centre and by the European Union's Erasmus+ Capacity-Building ENeA SEA Project and Seventh Framework Programme (FP7/2007-2013), projects EarlyNutrition and ODIN under grant agreement numbers 289346 and 613977.

\section{Availability of data and materials}

The dataset supporting the conclusions of this article can be made available upon request, and after approval by the GUSTO Executive Committee.

Ethics approval and consent to participate

All participating pregnant women signed written informed consent for themselves and on behalf of their offspring at enrolment. The study received ethical approval from the National Healthcare Group Domain Specific Review Board and the SingHealth Centralised Institutional Review Board.

\section{Consent for publication}

Not applicable.

\section{Competing interests}

KMG and YSC report receiving reimbursement for speaking at conferences sponsored by companies selling nutritional products. KMG and YSC report being part of an academic consortium that has received research funding from Abbott Nutrition, Nestle and Danone. All other authors have no conflict of interest to declare. 


\section{Author details}

'Saw Swee Hock School of Public Health, National University of Singapore, Tahir Foundation Building (Block MD1), 12 Science Drive 2, \#09-01v, Singapore 117549, Singapore. ${ }^{2}$ Inserm, Centre for Research in Epidemiology and StatisticS (CRESS), Research team on Early life Origins of Health (EAROH), Villejuif, France. ${ }^{3}$ Agency for Science Technology and Research (A*STAR), Singapore Institute for Clinical Sciences (SICS), Singapore, Singapore. ${ }^{4}$ Department of Obstetrics \& Gynaecology, Yong Loo Lin School of Medicine, National University of Singapore, National University Health System, Singapore, Singapore. ${ }^{5}$ Department of Maternal Fetal Medicine, KK Women's and Children's Hospital, Singapore, Singapore. 'Duke-NUS Medical School, Singapore, Singapore. ${ }^{7}$ Department of Paediatrics, KK Women's and Children's Hospital, Singapore, Singapore. ${ }^{8}$ Lee Kong Chian School of Medicine, Nanyang Technological University, Singapore, Singapore. ${ }^{9}$ Department of Paediatrics, Yong Loo Lin School of Medicine, National University of Singapore, Singapore, Singapore. ${ }^{10}$ Division of Paediatric Allergy, Immunology \& Rheumatology, Khoo Teck Puat - National University Children's Medical Institute, National University Health System, Singapore, Singapore. ${ }^{11}$ Medical Research Council Lifecourse Epidemiology Unit, University of Southampton, Southampton, UK. ${ }^{12}$ NIHR Southampton Biomedical Research Centre, University of Southampton and University Hospital Southampton NHS Foundation Trust, Southampton, UK. ${ }^{13}$ Institute for Social Medicine, Epidemiology and Health Economics, Charite University Medical Centre, Berlin, Germany.

Received: 23 April 2019 Accepted: 13 August 2019 Published online: 22 August 2019

\section{References}

1. Janssen I, Leblanc AG. Systematic review of the health benefits of physical activity and fitness in school-aged children and youth. Int J Behav Nutr Phys Act. 2010;7:40

2. Lee IM, Shiroma EJ, Lobelo F, Puska P, Blair SN, Katzmarzyk PT, et al. Effect of physical inactivity on major non-communicable diseases worldwide: an analysis of burden of disease and life expectancy. Lancet. 2012;380(9838):219-29.

3. van Ekris E, Altenburg TM, Singh AS, Proper Kl, Heymans MW, Chinapaw MJ. An evidence-update on the prospective relationship between childhood sedentary behaviour and biomedical health indicators: a systematic review and meta-analysis. Obes Rev. 2016;17(9):833-49.

4. Chen B, van Dam RM, Tan CS, Chua HL, Wong PG, Bernard JY, et al. Screen viewing behavior and sleep duration among children aged 2 and below. BMC Public Health. 2019;19(1):59.

5. Itani O, Jike M, Watanabe N, Kaneita Y. Short sleep duration and health outcomes: a systematic review, meta-analysis, and meta-regression. Sleep Med. 2017:32:246-56.

6. Cespedes Feliciano EM, Quante M, Rifas-Shiman SL, Redline S, Oken E, Taveras EM. Objective Sleep Characteristics and Cardiometabolic Health in Young Adolescents. Pediatrics. 2018;142(1):1-14.

7. Padmapriya N, Aris IM, Tint MT, Loy SL, Cai S, Tan KH, et al. Sex-specific longitudinal associations of screen viewing time in children at 2-3 years with adiposity at 3-5 years. Int J Obes (Lond). 2019;43(7):1334-43.

8. Carson V, Tremblay MS, Chaput JP, Chastin SF. Associations between sleep duration, sedentary time, physical activity, and health indicators among Canadian children and youth using compositional analyses. Appl Physiol Nutr Metab. 2016;41(6 Suppl 3):S294-302.

9. Kuzik N, Poitras VJ, Tremblay MS, Lee EY, Hunter S, Carson V. Systematic review of the relationships between combinations of movement behaviours and health indicators in the early years (0-4 years). BMC Public Health. 2017; 17(Suppl 5):849.

10. Certain LK, Kahn RS. Prevalence, correlates, and trajectory of television viewing among infants and toddlers. Pediatrics. 2002;109(4):634-42.

11. Tremblay MS, Carson V, Chaput JP, Connor Gorber S, Dinh T, Duggan M, et al. Canadian 24-hour movement guidelines for children and youth: an integration of physical activity, sedentary behaviour, and sleep. Appl Physiol Nutr Metab. 2016:41(6 Suppl 3):S311-27.

12. Tremblay MS, Chaput J-P, Adamo KB, Aubert S, Barnes JD, Choquette L, et al. Canadian 24-hour movement guidelines for the early years ( $0-4$ years): an integration of physical activity, sedentary behaviour, and sleep. BMC Public Health. 2017;17(5):874.
13. Okely AD, Ghersi D, Hesketh KD, Santos R, Loughran SP, Cliff DP, et al. A collaborative approach to adopting/adapting guidelines - the Australian 24hour movement guidelines for the early years (birth to 5 years): an integration of physical activity, sedentary behavior, and sleep. BMC Public Health. 2017;17(5):869.

14. Australian 24-Hour Movement Guidelines for Children and Young People (517 years) - An Integration of Physical Activity, Sedentary Behaviour and Sleep. Canberra: Department of Health, Australian Government; 2019.

15. Africa SSloS. South African 24-hour movement guidelines for birth to five years: an integration of physical activity, sitting behaviour, screen time and sleep. 2018.

16. World Health Organization. Guidelines on physical activity, sedentary behaviour and sleep for children under 5 years of age. Geneva: World Health Organization; 2019.

17. Walsh JJ, Barnes JD, Cameron JD, Goldfield GS, Chaput J-P, Gunnell KE, et al. Associations between 24 hour movement behaviours and global cognition in US children: a cross-sectional observational study. The Lancet Child \& Adolesc Health. 2018;2(11):783-91.

18. Carson V, Chaput JP, Janssen I, Tremblay MS. Health associations with meeting new 24-hour movement guidelines for Canadian children and youth. Prev Med. 2017;95:7-13.

19. Roman-Vinas B, Chaput JP, Katzmarzyk PT, Fogelholm M, Lambert EV, Maher

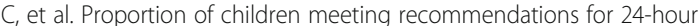
movement guidelines and associations with adiposity in a 12-country study. Int J Behav Nutr Phys Act. 2016;13(1):123.

20. Lee EY, Hesketh KD, Hunter S, Kuzik N, Rhodes RE, Rinaldi CM, et al. Meeting new Canadian 24-hour movement guidelines for the early years and associations with adiposity among toddlers living in Edmonton. Canada BMC Public Health. 2017;17(Suppl 5):840.

21. Roberts KC, Yao X, Carson V, Chaput JP, Janssen I, Tremblay MS. Meeting the Canadian 24-hour movement guidelines for children and youth. Health Rep. 2017;28(10):3-7.

22. Chaput JP, Colley RC, Aubert S, Carson V, Janssen I, Roberts KC, et al. Proportion of preschool-aged children meeting the Canadian 24-hour movement guidelines and associations with adiposity: results from the Canadian health measures survey. BMC Public Health. 2017;17(Suppl 5):829.

23. Cliff DP, McNeill J, Vella SA, Howard SJ, Santos R, Batterham M, et al. Adherence to 24-hour movement guidelines for the early years and associations with social-cognitive development among Australian preschool children. BMC Public Health. 2017;17(Suppl 5):857.

24. Lee ST, Wong JE, Ong WW, Ismail MN, Deurenberg P, Poh BK. Physical activity pattern of Malaysian preschoolers: environment, barriers, and motivators for active play. Asia Pac J Public Health. 2016;28(5 Suppl):21S-34S.

25. Bernard JY, Padmapriya N, Chen B, Cai S, Tan KH, Yap F, et al. Predictors of screen viewing time in young Singaporean children: the GUSTO cohort. Int J Behav Nutr Phys Act. 2017;14(1):112.

26. Olds T, Blunden S, Petkov J, Forchino F. The relationships between sex, age, geography and time in bed in adolescents: a meta-analysis of data from 23 countries. Sleep Med Rev. 2010;14(6):371-8.

27. Hinkley T, Crawford D, Salmon J, Okely AD, Hesketh K. Preschool children and physical activity: a review of correlates. Am J Prev Med. 2008;34(5):435-41.

28. Hinkley T, Salmon J, Okely AD, Trost SG. Correlates of sedentary behaviours in preschool children: a review. Int J Behav Nutr Phys Act. 2010;7:66.

29. Stephenson J, Heslehurst N, Hall J, Schoenaker D, Hutchinson J, Cade JE, et al. Before the beginning: nutrition and lifestyle in the preconception period and its importance for future health. Lancet. 2018;391(10132):1830-41.

30. Padmapriya N, Bernard JY, Liang S, Loy SL, Shen Z, Kwek K, et al. Association of physical activity and sedentary behavior with depression and anxiety symptoms during pregnancy in a multiethnic cohort of Asian women. Arch Womens Ment Health. 2016;19(6):1119-28.

31. Soh SE, Tint MT, Gluckman PD, Godfrey KM, Rifkin-Graboi A, Chan YH, et al. Cohort profile: growing up in Singapore towards healthy outcomes (GUSTO) birth cohort study. Int J Epidemiol. 2014;43(5):1401-9.

32. Stegenga $H$, Haines A, Jones K, Wilding J, Guideline DG. Identification, assessment, and management of overweight and obesity: summary of updated NICE guidance. BMJ. 2014;349:96608.

33. Inskip HM, Godfrey KM, Robinson SM, Law CM, Barker DJ, Cooper C, et al. Cohort profile: the Southampton Women's survey. Int J Epidemiol. 2006;35(1):42-8.

34. Padmapriya N, Shen L, Soh SE, Shen Z, Kwek K, Godfrey KM, et al. Physical activity and sedentary behavior patterns before and during pregnancy in a multi-ethnic sample of Asian women in Singapore. Matern Child Health J. 2015;19(11):2523-35. 
35. The IPAQ Group (2015). Guidelines for Data Processing and Analysis of the International Physical Activity Questionnaire.

36. Jago R, Stamatakis E, Gama A, Carvalhal IM, Nogueira H, Rosado V, et al. Parent and child screen-viewing time and home media environment. Am J Prev Med. 2012;43(2):150-8.

37. Hirshkowitz M, Whiton K, Albert SM, Alessi C, Bruni O, DonCarlos L, et al. National Sleep Foundation's updated sleep duration recommendations: final report. Sleep Health. 2015;1 (4):233-43.

38. van Hees VT, Gorzelniak L, Dean Leon EC, Eder M, Pias M, Taherian S, et al. Separating movement and gravity components in an acceleration signal and implications for the assessment of human daily physical activity. PLoS One. 2013;8(4):e61691.

39. van Hees VT, Fang Z, Langford J, Assah F, Mohammad A, da Silva IC, et al. Autocalibration of accelerometer data for free-living physical activity assessment using local gravity and temperature: an evaluation on four continents. J Appl Physiol (1985). 2014;117(7):738-44.

40. Sabia S, Cogranne P, van Hees VT, Bell JA, Elbaz A, Kivimaki M, et al. Physical activity and adiposity markers at older ages: accelerometer vs questionnaire data. J Am Med Dir Assoc. 2015;16(5):438 e7-13.

41. van Hees VT, Sabia S, Anderson KN, Denton SJ, Oliver J, Catt M, et al. A novel, open access method to assess sleep duration using a wrist-worn accelerometer. PLoS One. 2015;10(11):e0142533.

42. Hildebrand M, Hansen BH, van Hees VT, Ekelund U. Evaluation of raw acceleration sedentary thresholds in children and adults. Scand J Med Sci Sports. 2017;27(12):1814-23.

43. Dwyer GM, Hardy LL, Peat JK, Baur LA. The validity and reliability of a home environment preschool-age physical activity questionnaire (pre-PAQ). Int J Behav Nutr Phys Act. 2011;8:86.

44. Katzmarzyk PT, Staiano AE. Relationship between meeting 24-hour movement guidelines and Cardiometabolic risk factors in children. J Phys Act Health. 2017;14(10):779-84

45. Lee I-F. Contemporary childhoods in Asia: becoming (pre) school students in Hong Kong. Glob I Stud Childhood. 2014;4(3):157-68.

46. Jerrim J. Why do east Asian children perform so well in PISA? An investigation of Western-born children of east Asian descent. Oxf Rev Educ. 2015;41(3):310-33.

47. Aishworiya R, Chan P, Kiing J, Chong SC, Laino AG, Tay S. Sleep behaviour in a sample of preschool children in Singapore. Ann Acad Med Singap. 2012:41(3):99-104.

48. Tso W, Rao N, Jiang F, Li AM, Lee SL, Ho FK, et al. Sleep duration and school readiness of Chinese preschool children. J Pediatr. 2016;169:266-71.

49. Komada Y, Abe T, Okajima I, Asaoka S, Matsuura N, Usui A, et al. Short sleep duration and irregular bedtime are associated with increased behavioral problems among Japanese preschool-age children. Tohoku J Exp Med. 2011;224(2):127-36.

50. Williams JA, Zimmerman FJ, Bell JF. Norms and trends of sleep time among US children and adolescents. JAMA Pediatr. 2013;167(1):55-60.

51. Iglowstein I, Jenni OG, Molinari L, Largo RH. Sleep duration from infancy to adolescence: reference values and generational trends. Pediatrics. 2003;111(2):302-7.

52. Mindell JA, Sadeh A, Kwon R, Goh DY. Cross-cultural differences in the sleep of preschool children. Sleep Med. 2013;14(12):1283-9.

53. Nakagawa M, Ohta H, Nagaoki Y, Shimabukuro R, Asaka Y, Takahashi N, et al. Daytime nap controls toddlers' night time sleep. Sci Rep. 2016;6:27246.

54. Mindell JA, Meltzer LJ, Carskadon MA, Chervin RD. Developmental aspects of sleep hygiene: findings from the 2004 National Sleep Foundation sleep in America poll. Sleep Med. 2009;10(7):771-9.

55. Okely AD, Tremblay MS, Reilly JJ, Draper CE, Bull F. Physical activity, sedentary behaviour, and sleep: movement behaviours in early life. Lancet Child Adolesc Health. 2018;2(4):233-5.

56. Moore LL, Lombardi DA, White MJ, Campbell JL, Oliveria SA, Ellison RC Influence of parents' physical activity levels on activity levels of young children. J Pediatr. 1991;118(2):215-9.

57. Sallis JF, Patterson TL, McKenzie TL, Nader PR. Family variables and physical activity in preschool children. J Dev Behav Pediatr. 1988;9(2):57-61.

58. Davison KK, Francis LA, Birch LL. Links between parents' and girls' television viewing behaviors: a longitudinal examination. J Pediatr. 2005;147(4):436-42.

59. Busch V, Altenburg TM, Harmsen IA, Chinapaw MJ. Interventions that stimulate healthy sleep in school-aged children: a systematic literature review. Eur J Pub Health. 2017;27(1):53-65.

60. Golley RK, Hendrie GA, Slater A, Corsini N. Interventions that involve parents to improve children's weight-related nutrition intake and activity patterns - what nutrition and activity targets and behaviour change techniques are associated with intervention effectiveness? Obes Rev. 2011;12(2):114-30.

61. Uijtdewilligen L, Waters CN, Muller-Riemenschneider F, Lim YW. Preventing childhood obesity in Asia: an overview of intervention programmes. Obes Rev. 2016;17(11):1103-15.

62. Harvey-Berino J, Rourke J. Obesity prevention in preschool native-american children: a pilot study using home visiting. Obes Res. 2003;11(5):606-11.

63. Blair PS, Humphreys JS, Gringras P, Taheri S, Scott N, Emond A, et al. Childhood sleep duration and associated demographic characteristics in an English cohort. Sleep. 2012;35(3):353-60.

64. Ruiz R, Gesell SB, Buchowski MS, Lambert W, Barkin SL. The relationship between hispanic parents and their preschool-aged children's physical activity. Pediatrics. 2011;127(5):888-95.

65. Sallis JF, Prochaska JJ, Taylor WC. A review of correlates of physical activity of children and adolescents. Med Sci Sports Exerc. 2000;32(5):963-75.

66. Van Der Horst K, Paw MJ, Twisk JW, Van Mechelen W. A brief review on correlates of physical activity and sedentariness in youth. Med Sci Sports Exerc. 2007;39(8):1241-50.

67. McDonald $\mathrm{L}$, Wardle J, Llewellyn $\mathrm{CH}$, van Jaarsveld $\mathrm{CH}$, Fisher A. Predictors of shorter sleep in early childhood. Sleep Med. 2014;15(5):536-40.

68. Natal $C L$, Lourenco TJ, Silva LA, Boscolo RA, Silva A, Tufik $\mathrm{S}$, et al. Gender differences in the sleep habits of 11-13 year olds. Braz J Psychiatry. 2009;31(4):358-61.

69. Dollman J, Ridley K, Olds T, Lowe E. Trends in the duration of school-day sleep among 10- to 15-year-old south Australians between 1985 and 2004. Acta Paediatr. 2007:96(7):1011-4.

70. Huang WY, Wong SH, Salmon J. Correlates of physical activity and screenbased behaviors in Chinese children. J Sci Med Sport. 2013;16(6):509-14.

71. Atkin AJ, Sharp SJ, Corder K, van Sluijs EM. International Children's Accelerometry database $\mathrm{C}$. prevalence and correlates of screen time in youth: an international perspective. Am J Prev Med. 2014;47(6):803-7.

72. Tremblay MS, Barnes JD, González SA, Katzmarzyk PT, Onywera VO, Reilly JJ, et al. Global matrix 2.0: report card grades on the physical activity of children and youth comparing 38 countries. J Phys Act Health. 2016;13(11 Suppl 2):S343-S66.

73. Lin LY, Cherng RJ, Chen YJ. Relationship between time use in physical activity and gross motor performance of preschool children. Aust Occup Ther J. 2017;64(1):49-57.

74. Bell AC, Finch M, Wolfenden L, Fitzgerald M, Morgan PJ, Jones J, et al. Child physical activity levels and associations with modifiable characteristics in Centre-based childcare. Aust N Z J Public Health. 2015;39(3):232-6.

\section{Publisher's Note}

Springer Nature remains neutral with regard to jurisdictional claims in published maps and institutional affiliations.

Ready to submit your research? Choose BMC and benefit from:

- fast, convenient online submission

- thorough peer review by experienced researchers in your field

- rapid publication on acceptance

- support for research data, including large and complex data types

- gold Open Access which fosters wider collaboration and increased citations

- maximum visibility for your research: over $100 \mathrm{M}$ website views per year

At $\mathrm{BMC}$, research is always in progress.

Learn more biomedcentral.com/submission 